\title{
SARS-CoV2 S Protein Features Potential Estrogen Binding Site
}

\section{Ante Tomasovićc ${ }^{*}$, \\ Damir Stanzer®e, Ivan Krešimir Svetec(10 and Marina Svetec Miklenić ${ }^{*}$ \\ Faculty of Food Technology and Biotechnology, University of Zagreb, Pierottijeva 6, 10000 Zagreb, Croatia}

Received: 27 May 2020

Accepted: 8 February 2021

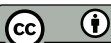

*Corresponding author: E-mail:antomasov@gmail.com E-mail:mmiklenic@pbf.hr Phone: +38514836013

\begin{abstract}
SUMMARY
Research background. During the current SARS-CoV2 pandemic, as well as earlier SARS and MERS epidemics, it has been observed that COVID19-positive women on average tend to have milder symptoms and lower fatality rates than men. There is a number of differences between the sexes known to contribute to different immune responses and severity of the disease, one being the effect of estrogen via estrogen receptor signalling. We wondered if estrogen might also affect the SARS-CoV2 more directly, perhaps by binding to the surface glycoprotein (S protein), thus possibly reducing its infectivity.

Experimental approach. To assess whether there is a possibility for estrogen binding on the SARS-CoV2 S protein, we used BLAST and HHpred to compare protein sequences of $S$ protein and human estrogen receptor $\beta$, while 3D structures of a potential estrogen binding site and an active site of estrogen receptor $\beta$ were visualized and compared using PyMOL.

Results and conclusions. By comparing the sequence of SARS-CoV2 S protein with the human estrogen receptor $\beta$, we identified a potential estrogen binding site on $S$ protein and further determined that it also shares notable similarities with the active site of ER $\beta$ when observed in 3D structure of their respective proteins. As a control, SARS-CoV2 S protein was compared with the human androgen receptor, and no such similarities were found. The potential estrogen binding site is part of coronavirus $\mathrm{S} 2$ superfamily domain, which is involved in host-virus membrane fusion during infection and appears to be conserved throughout the Coronaviridae family.

Novelty and scientific contribution: This preliminary communication shows that SARS-CoV2 S protein features a potential estrogen binding site. Hopefully, this will prompt a more comprehensive study on the possibilities of estrogen binding on the $S$ protein and the effect this might confer on the virus infectivity.
\end{abstract}

Key words: SARS-CoV2, coronavirus, S protein, estrogen, estradiol, estrogen binding site

\section{INTRODUCTION}

The COVID-19 pandemic that has resulted in high numbers of critically ill patients and deaths is caused by novel coronavirus SARS-CoV2. Studies on the infection and clinical management reported sex differences in severity and outcome of the COVID-19 disease (1-7). It is known that males are more susceptible to influenza and common cold than females of the same age (8-10). Two other coronaviruses that also cause severe respiratory illness as SARS-CoV2 does, severe acute respiratory syndrome coronavirus (SARS-CoV) and the Middle East respiratory syndrome coronavirus (MERS-CoV) with a nucleotide identity to SARS-CoV2 of 79 and $50 \%$ respectively (11), also tend to be more severe and fatal in men than in women (12-15).

Besides lifestyle factors, the sex-specific difference in coronavirus susceptibility and disease outcomes is caused by sex differences in the immune response, both innate and adaptive (16). One of the explanations for this sex difference in COVID-19 susceptibility is chromosomal: $X$ chromosome contains more immune-related genes than the $Y$ chromosome, and activation of these genes leads to stronger female immune response to viral 
infection $(7,17,18)$. Another explanation is hormonal: hormones, such as estrogen, which females produce in larger quantities than males, help to defend against coronaviruses like MERS-CoV, SARS-CoV and SARS-CoV2. There are various possible explanations of estrogen protective action mechanism (19-24). Among the effects of estrogen in the immune defence, there is an influence on adaptive immunity fighters, $\mathrm{T}$ - and $\mathrm{B}$-cells, by impairing negative selection of high affinity auto-reactive $B$ cells, modulating $B$ cell function and leading to Th2 response (25), and induction of $T$ cell homing by enhancing the expression of CCR5, a homing marker (26). An experiment performed with mice infected with mouse-adapted SARS-CoV MA15 (27) showed that the male mice were more susceptible to the SARS infection than females, and that the female mice that had their estrogen-producing ovaries removed or were treated with an estrogen-receptor blocker had higher fatality rates than those with normal estrogen function. The sex-specific differences were independent of $\mathrm{T}$ and $\mathrm{B}$ cell responses. Therefore, these results suggest that estrogen receptor (ER) signalling in females suppressed the accumulation and function of inflammatory monocyte macrophages in the lungs and/or directly suppressed SARS-CoV replication via effects on cellular metabolism.

Besides acting on ER signalling as a mechanism of conferring strong positive effect on disease outcomes and fatality rate (25), we considered the idea that the estrogen might act directly on the virus. We hypothesized that the estrogen molecule might bind on the virus surface and thus reduce its infectivity. Since spike (S) protein is the major surface protein the SARS-CoV2 employs to bind to the human receptor and initiate fusion with the host cell (26-29), we wondered if there was any theoretical possibility that estrogen could bind to this protein. If this were indeed the case, then estrogen and estrogen-like molecules might have a therapeutic effect. To get some insight into these questions, we first performed protein BLAST to determine if there was any similarity between SARS-CoV2 S protein and the human ER $\beta$ sequences. Although these two proteins originate from different species and differ greatly in their overall size, a sequence similarity was found in regions which correspond to the estrogen binding site of the human ER $\beta$. We further explored the spatial structure of potential estrogen binding site on S protein using PyMol software and again found substantial similarities with the $3 D$ structure of binding site on the human ER $\beta$.

\section{MATERIALS AND METHODS}

\section{Protein sequences and 3D structures}

The following protein sequences were downloaded from $\mathrm{NCBI}$ (30): human ER $\beta$ sequence (UniProtKB/Swiss-Prot: Q92731.2), human androgen (dihydrotestosterone) receptor (UniProtKB/Swiss-Prot: P10275.3), SARS-CoV2 surface glycoprotein (NCBI reference sequence: YP_009724390.1) and SARS CoV Urbani spike protein (GenBank: AYV99817.1). The following 3D structures were downloaded from RCSB Protein Data Bank (31): crystal structure of ER $\beta$ bound to estradiol (PDB ID: 5TOA (32)), crystal structure of human androgen receptor ligand-binding domain in complex with dihydrotestosterone (PDB ID: 2AMA (33)) and prefusion 2019-nCoV spike glycoprotein with a single receptor-binding domain up (PDB ID: 6VSB (29)).

\section{Bioinformatic tools}

Protein sequence alignment and analysis were performed using protein BLAST (34) and the HHpred server for remote protein homology detection and structure prediction (https://toolkit.tuebingen.mpg.de/tools/hhpred (35)). In all cases, standard algorithm parameters were used $(36,37)$. For $3 \mathrm{D}$ protein structure, visualization the PyMOL software was used (38).

\section{RESULTS AND DISCUSSION}

To assess whether there could be any possibilities for the $\mathrm{S}$ protein of SARS-CoV2 to contain a site that might bind estrogen, we used protein BLAST to compare its sequence with human ER $\beta$. We found three regions of similarity. The two more significant were: a region of 19 amino acids starting from amino acid 319 of the ER $\beta$ and amino acid 817 of $S$ protein with $73 \%$ positives without gaps (e-value 2.5 ) and a region of 14 amino acids starting from amino acid 385 of the ER $\beta$ and amino acid 236 of S protein with $64 \%$ positives without gaps (e-value 3.2). Although the e-values were relatively high, we found it interesting that both of these two regions are annotated in NCBI as part of the ligand-binding domain of the estrogen receptor.

Furthermore, we visualized the 3D structure of the SARS-CoV2 S protein, using PyMOL software (38), and compared it to the 3D structure of ER $\beta$ to check whether the regions of $S$ protein carrying either the 19 or 14 amino acid alignments found by BLAST bear any spatial resemblance to the estrogen binding site of ER $\beta$ and thus could constitute a potential estrogen binding site on the $S$ protein. According to the $3 D$ structure analysis, the 19 amino acid region (319F to 337E) appears to play an important role in the ligand-binding domain on the ER $\beta$ (Fig. 1a) since it protrudes into the active site with the methionine $336 \mathrm{M}$ as the closest amino acid to the estradiol (a major form of estrogen in women of reproductive age) when bound. The residue $336 \mathrm{M}$ is less than $5 \AA$ apart from the estradiol molecule (Fig. 1b). Therefore, it is reasonable to assume that the terminal part of the 19 amino acid alignment constitutes a part of an active site on ER $\beta$. Residues involved in ligand-binding on $E R \beta$ are glutamate $305 E$ situated on the first alpha helix and the glycine $472 \mathrm{G}$ and histidine $475 \mathrm{H}$ situated on the second alpha helix, which form three polar bonds with estradiol (Fig. 1c).

In the SARS-CoV2 S protein, the 19 amino acid alignment begins with phenylalanine 817F. In the corresponding 3D structure obtained by electron micrograph (29) residues $817 \mathrm{~F}$ 

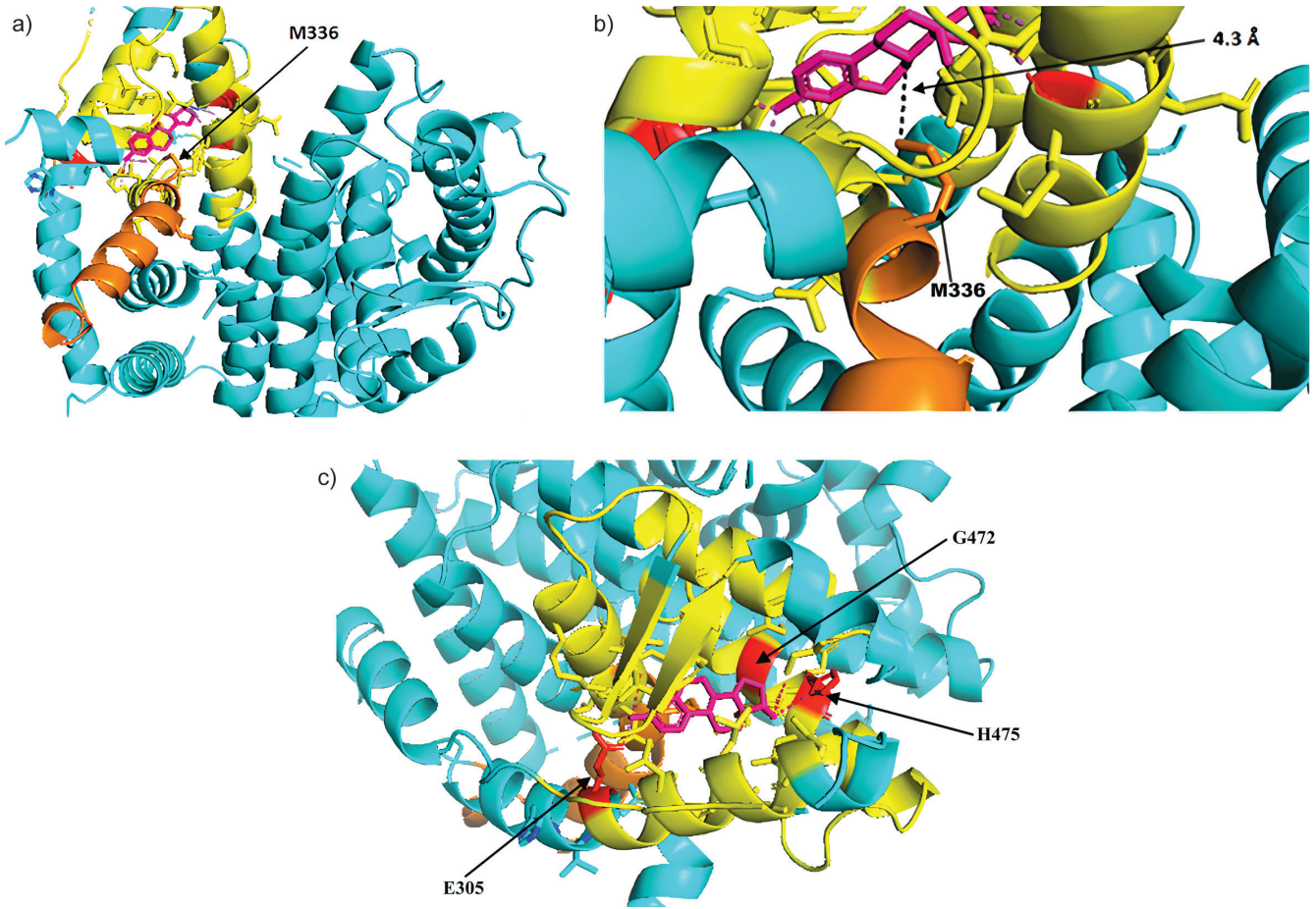

Fig. 1. The 3D structure of: a) human estrogen receptor $\beta$ in the vicinity of 19 amino acid sequence alignment with the $S$ protein spanning residues from F319 do E337 (orange) with estradiol (magenta) bound to the active site, b) the alignment ends with M336 protruding into the active site and being less than $5 \AA$ from the estradiol molecule, and c) the active site seen from different perspective offers better view of other surrounding residues likely involved in binding (yellow) and the three residues (E305, G472 and H475, marked red) which can form polar bonds with estradiol

through $828 \mathrm{~L}$ can be found. Unfortunately, the structure contains a brakeage of protein chain between the residues 811 and 815 as well as 828 and 853 resulting in separation of this part of the molecule. Moreover, the protein chain breakage visible in the 3D structure of SARS-CoV2 S protein is present at the approximately same site in the SARS-CoV Urbani 3D structure (the related coronavirus causing SARS pandemic in 2003), indicating that this particular site is sensitive to sample preparation and manipulation. However, the separated alpha helix is located near the breakage site, indicating that it has not moved considerably from its native position (Fig. 2). Instead of methionine $336 \mathrm{M}$ present in the analyzed 19 amino acid region on ER $\beta$, the corresponding region on $S$ protein contains an analogue nonpolar residue isoleucine 8341 scored as positive by BLAST. Although the exact position of $834 \mathrm{I}$ in the available model of $S$ protein cannot be observed due to the protein chain breakage, it can be positioned in space based on the surrounding residues. We then tried to identify the amino acids that might be close in space to the 834I and could form polar bonds with estradiol molecule. Using BLAST, we identified a region of S protein (residues 1045 to 1052), which aligns with the region of ER $\beta$ spanning residues 471 to 479 with $66 \%$ of them scored as positives, and which contains two key residues for estradiol binding on ER $\beta-472 \mathrm{G}$ and $475 \mathrm{H}$. The main difference is that on the $S$ protein the glycine and histidine are separated by one amino acid $(\mathrm{Y})$, while two residues in between are present on the ER $\beta$ ( $M$ and $E$ ). To find the potential analogue of the third amino acid responsible for estradiol binding on ER $\beta$ (305E), we used the HHpred server (35). The region spanning residues 289 to 310 of ER $\beta$ (containing 305E) was compared against the entire sequence of $S$ protein. The analysis resulted in region spanning residues from 1013 to 1033 of S protein identified as similar with two gaps introduced to achieve the alignment of $305 \mathrm{E}$ with its potential analogue on the $\mathrm{S}$ protein - the glutamate at position 1031.

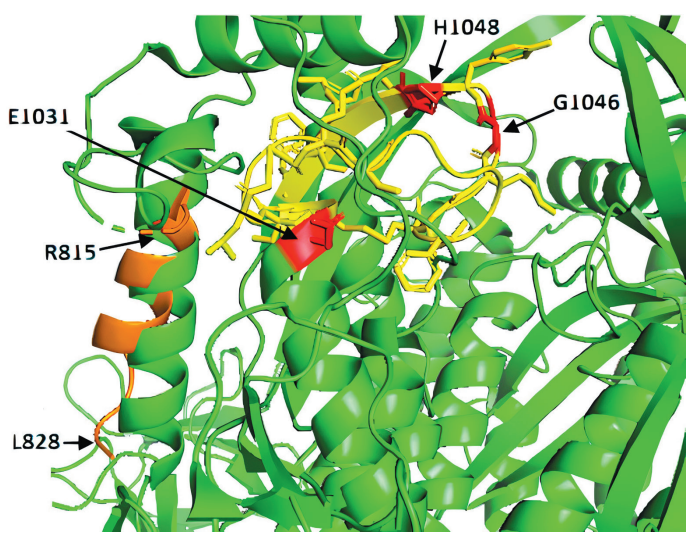

Fig. 2. The 3D structure of $S$ protein in the vicinity of potential estrogen binding site. The 19 amino acid sequence alignment with the region on $E R B$ is shown in orange. Residues R815 and L 828 are sites of protein chain breakage. Amino acids possibly involved in polar binding of estrogen in the potential active sites (E1031, G1046 and H1048) are marked red, while other residues surrounding the potential binding site are shown in yellow 
Finally, using PyMol (38), we visualized the spatial position of three amino acids, which can form polar bonds with the ligand (1046G, 1048H and 1031E) on the 3D structure of S protein and compared this site to the active site for estradiol binding on ER $\beta$. Histidine residue $1048 \mathrm{H}$ on the S protein was rotated in space around alpha $C$ atom to face towards the $1031 \mathrm{E}$, which is likely to occur in the case of estradiol binding. The three key amino acids on the ER $\beta$ responsible for polar binding of estradiol form a triangle with the length of its sides being 4.7, 12.8 and $14.8 \AA$ (Fig. 3a). On the S protein the three analogous amino acids form a triangle with sides 4.6, 14.8 and $11.3 \AA$ long (Fig. 3b). In other words, the dimensions of the space between the residues capable of forming polar bonds with estradiol in ER $\beta$ and the analyzed site on S protein are curiously similar, with the main difference being that the longest side of the triangle in the active site of ER $\beta$ is between histidine and glutamate and of the $S$ protein between glycine and glutamate. Moreover, besides the three residues with the potential of forming polar bonds with estradiol, a number of other residues surrounding the potential binding site on $\mathrm{S}$ protein are identical or similar in their chemical properties to that present in the ER $\beta$ active site (Figs. $3 c$ and $3 d$ ).

As a control, sequences and 3D structures of S protein and human androgen receptor were compared using the same methodology as described above. Although testosterone and estrogen are highly similar molecules and the estrogen and testosterone receptors share regions of notable similarity in the ligand-binding domain, we did not find sequence alignments of $\mathrm{S}$ protein with the androgen receptor that include all three key residues for testosterone binding $(R, T$ and $\mathrm{N})$, nor could we identify a site in the 3D structure of S protein that would share significant resemblance to the testosterone binding site (data not shown).

Taken together, our analyses suggest that SARS-CoV2 S protein features a potential estrogen binding site. Understandably, whether or not the estradiol molecule actually can bind to the potential site - and if it does bind, how it affects the $\mathrm{S}$ protein and the infectivity of the virus can be established only experimentally. The strong positive effect of estrogen on disease outcome and fatality rate was experimentally shown in mice using mouse-adapted SARS-CoV MA15 and the effect was explained by estrogen receptor signalling (27). The entire S protein of mouse-adapted strain differs in only one amino acid from the SARS-CoV, the human virus causing the SARS 2003 epidemic (27). Thus, we wondered if SARS-CoV, which is closely related to SARS-CoV2, also features a potential estrogen binding site and whether it is conceivable that at least to an extent the positive effect of
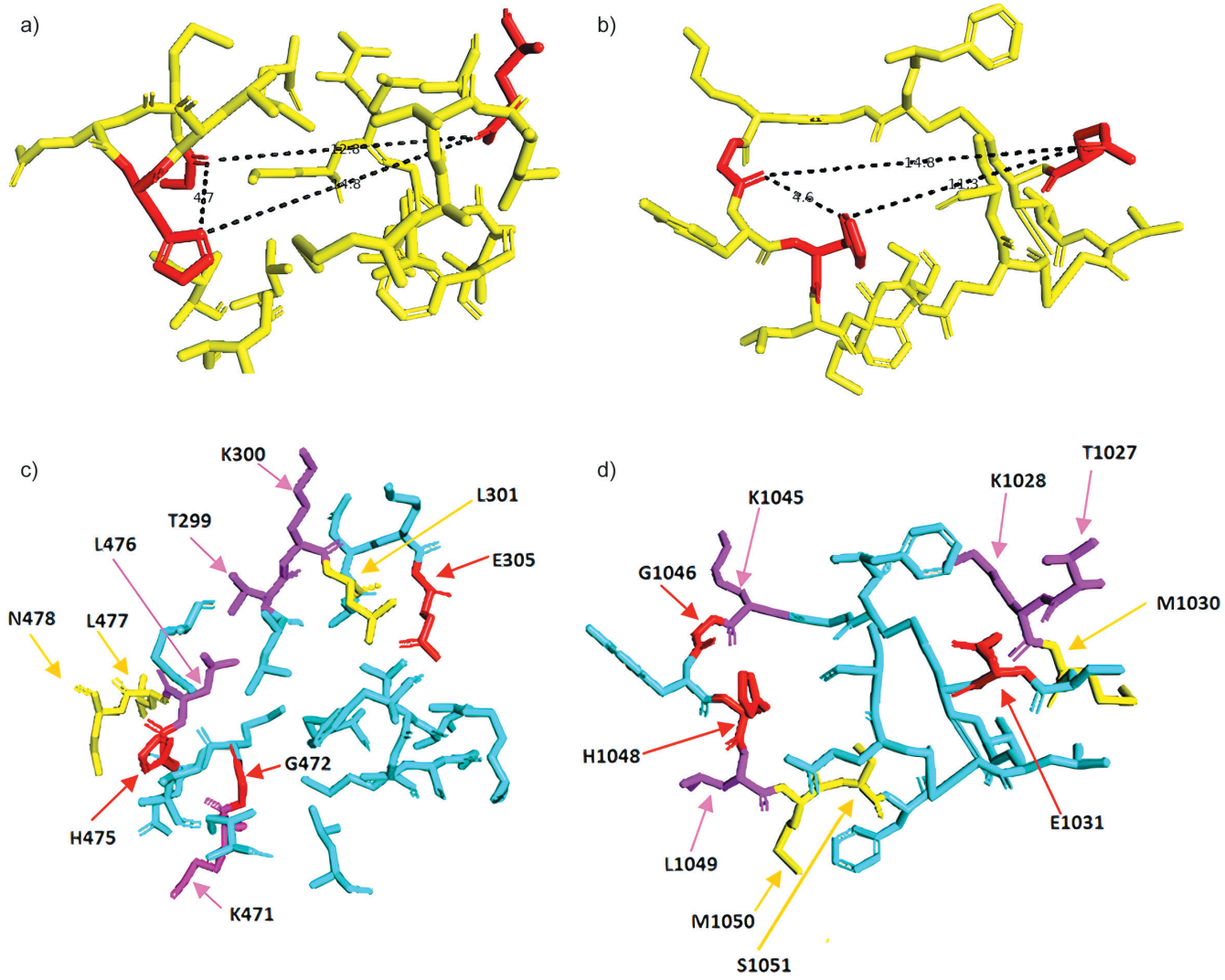

Fig. 3. Comparison of estrogen binding site of $E R \beta$ and potential estrogen binding site found on $S$ protein of SARS-CoV2. Amino acids $E$, G and $\mathrm{H}$ capable of forming polar bonds with estrogen are depicted red: a) sides of the triangle between $\mathrm{E}, \mathrm{G}$ and $\mathrm{H}$ residues are $4.7,12.8$ and $14.8 \AA \AA$ on ER $\beta$, and b) 4.6, $14.8 \mathrm{i} 11.3 \AA$ A on S protein, c) identical (red and purple) and similar (yellow) residues surrounding the estrogen binding site of ER $\beta$ compared with d) potential estrogen binding site on SARS-CoV2 S protein 


$\begin{array}{ll}\text { ACcession } & \text { Species } \\ \text { YP_009724390.1 } & \text { SARS-CoV2 } \\ \text { QIQ54048.1 } & \text { Pangolin coronavirus } \\ \text { QHR63300.2 } & \text { Bat coronavirus RaTG13 } \\ \text { QJE50589.1 } & \text { SARS coronavirus Urbani } \\ \text { ABN10911.1 } & \text { Bat coronavirus HKU9-1 } \\ \text { YP_001876437.1 } & \text { Beluga whale coronavirus SW1 } \\ \text { AE086768.1 } & \text { Duck coronavirus } \\ \text { CAC39300.1 } & \text { Avian infectious bronchitis virus (strain Beaudette US } \\ \text { ACT11007.1 } & \text { Bovine respiratory coronavirus AH187 } \\ \text { ACT11030.1 } & \text { Human enteric coronavirus strain 4408 } \\ \text { ARC95227.1 } & \text { Porcine hemagglutinating encephalomyelitis virus } \\ \text { ABD75513.1 } & \text { Human coronavirus HKU1 } \\ \text { AVV62537.1 } & \text { Middle East respiratory syndrome-related coronavirus } \\ \text { AFG25750.1 } & \text { Rat coronavirus } \\ \text { AIH06857.1 } & \text { Swine deltacoronavirus ohioCVM1/2014 } \\ \text { YP_004070194.1 } & \text { Feline infectious peritonitis virus } \\ \text { AIW52748.1 } & \text { Human coronavirus 229E } \\ \text { ASR18946.1 } & \text { Ferret systemic coronavirus } \\ \text { BBC54842.1 } & \text { Pigeon coronavirus UAE-HKU29 } \\ \text { AWJ64263.1 } & \text { Porcine enteric alphacoronavirus }\end{array}$

\begin{tabular}{|c|c|c|c|}
\hline 1025 & AATKMSECVLGQSKRVDFCGKGYHLMSFPQS & 1055 & \\
\hline 1021 & $\ldots \ldots \ldots \ldots \ldots \ldots \ldots \ldots \ldots \ldots \ldots \ldots \ldots \ldots \ldots \ldots$ & 1051 & $5 e-20$ \\
\hline 1021 & $\ldots \ldots \ldots \ldots \ldots \ldots \ldots \ldots$ & 1051 & $5 e-20$ \\
\hline 1008 & $\ldots \ldots \ldots \ldots \ldots \ldots \ldots \ldots \ldots \ldots \ldots \ldots \ldots \ldots \ldots$ & 1038 & $1 e-19$ \\
\hline 1022 & ..Q.I....KA..L.N....N.T.VL.I.. & 1051 & $1 e-10$ \\
\hline 1187 & ..E.IN...KST.N.YG...N.A.II....N & 1217 & $7 e-10$ \\
\hline 901 & .TQ.IN...KS. .N.YG...S.R.VL.I..N & 931 & $4 e-09$ \\
\hline 898 & 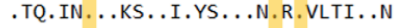 & 928 & $2 e-08$ \\
\hline 1119 & .ME.VN. ..KS..S.IN...N.N.II.LV.N & 1149 & $2 e-08$ \\
\hline 1119 & .ME.VN...KS..S.IN...N.N.II.LV.N & 1149 & $2 e-08$ \\
\hline 1104 & .IE.VN...KS..S.IN...N.N.II.LV.N & 1134 & $2 e-08$ \\
\hline 1106 & .IE.VN...KS..P.IN...N.N.IL.LV.N & 1136 & $3 e-08$ \\
\hline 1095 & .SD.VN...KS....NG...S.T.IV.. & 1122 & $3 e-08$ \\
\hline 1111 & .IE.VN...KS..P.IN...N.N.IL.LV.N & 1141 & $4 e-08$ \\
\hline 894 & .QQ.IN...KS..S.YG...N.T.IF.LT.T & 924 & $6 e-08$ \\
\hline 1183 &. KD.VN...RS..Q.FG...N.T. .F. LANA & 1213 & $1 e-07$ \\
\hline 907 & .QQ.VN...KS....YG...N.T.IF.L & 934 & $1 e-07$ \\
\hline 1182 & .KE.IN...RS..S.FG...N.T..F.LANA & 1212 & $2 e-07$ \\
\hline 934 & .ND.IN...KS..S.YG...N.T..F. & 960 & $3 e-07$ \\
\hline 883 & IN...YA..L.NG...Q.L.VL.LM.N & 909 & $1 e-06$ \\
\hline
\end{tabular}

Fig. 4. Results of BLAST analysis of SARS-CoV2 S protein region from 1025 to 1055 against S proteins of 20 randomly chosen species across the Coronaviridae family. Dots in the alignment represent identical amino acids. Yellow squares outline the key amino acids (E, $\mathrm{G}$ and $\mathrm{H}$ ) identified as having potential for estradiol binding on SARS-CoV2 S protein

estrogen observed in these experiments might be due to the $S$ protein binding estrogen. The BLAST analysis revealed that in the region 800-1273, which includes the potential estrogen binding site, the two $S$ proteins are $93 \%$ identical (with $97 \%$ amino acids scored as positives without gaps). The 3D structure of SARS-CoV also presented the same conformation in the investigated region with the potential estrogen binding site present (data not shown).

Moreover, the entire region of SARS-Cov2 S protein ranging from residue 662 to 1270 is a conserved S2 domain belonging to the coronavirus $\mathrm{S} 2$ superfamily. After transcription, the S protein is cleaved to S1 and S2 subunits. The S1 is responsible for binding to the host receptor, while the S2 subunit contains machinery for fusion with the host cell which consists of several distinct regions: the fusion peptide, heptad repeats 1 and 2 (HR1 and HR2) and transmembrane domain (39). The potential estrogen binding site identified in this work lies in the region carrying a linker between the two heptad repeats (40). A BLAST analysis of SARS-CoV2 S protein region 1025 to 1055 against S proteins of 20 randomly chosen species across the Coronaviridae family showed that this site is conserved, with the three amino acids ( $E, G$ and $H$ ) likely capable of forming polar bonds with estradiol together with some of the surrounding amino acids being present across the family (Fig. 4). Given the similarities of this region to the $E R \beta$, it is possible that an ancestral viral species at some point in time integrated a section of an ER from its host (41). However, it seems that this section might have taken on an important role in the coronavirus infectivity as a part $\mathbf{2}$ domain, perhaps being involved in host-virus membrane fusion by binding of other molecules featuring four rings, such as cholesterol. Thus, binding of estrogen might compete with the natural ligand for this site or cause conformational changes leading to reduced function of $\mathrm{S} 2$ domain and diminished infectivity.
Given the differences in COVID19 disease outcomes and fatality rate between men and women, the usage of estradiol to reduce severity of COVID19 infection is currently being tested in a phase II clinical trial in Stony Brook University Hospital, New York, NY, USA (https://clinicaltrials.gov/ct2/show/ NCT04359329). The positive and suspected to be positive patients are given estradiol patches delivering $100 \mu \mathrm{g} /$ day of estradiol for 7 days and rates of hospitalization, transfer to intensive care unit, intubation and death are being monitored during the 30-day time frame and compared to the non-treated control. The study recruits men over the age of 18 and women over the age of 55. Hopefully, although preliminary, the results presented in this work will inspire more researchers into investigating estrogen and estrogen-like molecules for treating COVID-19 since using different drugs, doses and methods of delivery could all affect the final result.

\section{CONCLUSIONS}

In this work, we identified a conserved potential estrogen binding site on SARS-CoV2 surface glycoprotein (S protein). This result could offer additional explanation of the better disease outcomes for COVID19 positive women than men, as well as of the strong protective effect of estrogen in experimental animals. Most importantly, this result could prompt other researchers to experimentally prove whether or not the estrogen can indeed bind to the $S$ protein and what effect would that confer on the infectivity of the virus. Hopefully, estrogen or estrogen-like molecule might be used to treat SARS-CoV2 infection or alleviate symptoms.

\section{FUNDING}

This research did not receive any specific grant from funding agencies in the public, commercial, or not-for-profit sectors. 


\section{CONFLICT OF INTEREST}

Authors declare no conflict of interest.

\section{AUTHORS' CONTRIBUTION}

All authors contributed in processing and interpreting the data, preparation, writing and revising of manuscript. A.T. and M.S.M. contributed in designing and performing experiments.

\section{ORCID ID}

A. Tomasović (1) https://orcid.org/0000-0002-4923-1403

D. Stanzer (1) https://orcid.org/0000-0002-8720-9063

I.K. Svetec (1) https://orcid.org/0000-0002-0469-2652

M. Svetec Miklenić 이 https://orcid.org/0000-0002-2438-7903

\section{REFERENCES}

1. Cai H. Sex difference and smoking predisposition in patients with COVID-19. Lancet Respir Med. 2020;8(4):e20. https://doi.org/10.1016/S2213-2600(20)30117-X

2. Zhao Y, Zhao Z, Wang Y, Zhou Y, Ma Y, Zuo W. Single-cell RNA expression profiling of ACE2, the receptor of SARSCoV-2. Am J Respir Crit Care Med. 2020;202(5):756-9. https://doi.org/10.1164/rccm.202001-0179LE

3. Yang X, Yu Y, Xu J, Shu H, Xia J, Liu H, et al. Clinical course and outcomes of critically ill patients with SARS-CoV-2 pneumonia in Wuhan, China: A single-centered, retrospective, observational study. Lancet Respir Med. 2020;8(5):475-81. https://doi.org/10.1016/S2213-2600(20)30079-5

4. Richardson, S, Hirsch JS, Narasimhan, M, Crawford JM, McGinn T, Davidson KW, the Northwell COVID-19 Research Consortium. Presenting characteristics, comorbidities, and outcomes among 5700 patients hospitalized with COVID-19 in the New York City area. JAMA. 2020;323(20):2052-9. https://doi.org/10.1001/jama.2020.6775

5. Dowd JB, Andriano L, Brazel DM, Rotondi V, Block P, Ding $X$, et al. Demographic science aids in understanding the spread and fatality rates of COVID-19. Proc Natl Acad Sci USA. 2020;117(18):9696-8.

https://doi.org/10.1073/pnas.2004911117

6. La Vignera S, Cannarella R, Condorelli RA, Torre F, Aversa A, Calogero AE. Sex-specific SARS-CoV-2 mortality: Among hormone-modulated ACE2 expression, risk of venous thromboembolism and hypovitaminosis D. Int J Mol Sci. 2020;21(8):2948-53.

https://doi.org/10.3390/ijms21082948

7. Conti P, Younes A. Coronavirus COV-19/SARS-CoV-2 affects women less than men: Clinical response to viral infection. J Biol Regul Homeost Agents. 2020;34(2):339-43.

https://doi.org/10.23812/Editorial-Conti-3
8. Wang XL, Yang L, Chan KH, Chan KP, Cao PH, Lau EH, et al. Age and sex differences in rates of influenza-associated hospitalizations in Hong Kong. Am J Epidemiol. 2015;182(4): 335-44.

https://doi.org/10.1093/aje/kwv068

9. Quandelacy, TM, Viboud C, Charu V, Lipsitch M, Goldstein E. Age- and sex-related risk factors for influenza-associated mortality in the United States between 1997-2007. Am J Epidemiol. 2014;179(2):156-67.

https://doi.org/10.1093/aje/kwt235

10. Macintyre S. Gender differences in the perceptions of common cold symptoms. Soc Sci Med. 1993;36(1):15-20. https://doi.org/10.1016/0277-9536(93)90301-J

11. Lu R, Zhao X, Li J, Niu P, Yang B, Wu H, et al. Genomic characterisation and epidemiology of 2019 novel coronavirus: Implications for virus origins and receptor binding. Lancet. 2020;395(10224):565-74.

https://doi.org/10.1016/S0140-6736(20)30251-8

12. Karlberg J, Chong DS, Lai WY. Do men have a higher case fatality rate of severe acute respiratory syndrome than women do? Am J Epidemiol. 2004;159(3):229-31. https://doi.org/10.1093/aje/kwh056

13. Alghamdi IG, Hussain II, Almalki SS, Alghamdi MS, Alghamdi MM, El-Sheemy MA. The pattern of Middle East respiratory syndrome coronavirus in Saudi Arabia: A descriptive epidemiological analysis of data from the Saudi Ministry of Health. Int J Gen Med. 2014;7:417-23.

https://doi.org/10.2147/IJGM.S67061

14. Matsuyama R, Nishiura H, Kutsuna S, Hayakawa K, Ohmagari N. Clinical determinants of the severity of Middle East respiratory syndrome (MERS): A systematic review and meta-analysis. BMC Public Health. 2016:16(1):1203-12. https://doi.org/10.1186/s12889-016-3881-4

15. Chen J, Subbarao K. The Immunobiology of SARS. Annu Rev Immunol. 2007;25:443-72.

https://doi.org/10.1146/annurev.immunol.25.022106.141706

16. Klein SL, Marriott I, Fish EN. Sex-based differences in immune function and responses to vaccination. Trans R Soc Trop Med Hyg. 2015;109(1):9-15.

https://doi.org/10.1093/trstmh/tru167

17. Klein SL, Flanagan KL. Sex differences in immune responses. Nat Rev Immunol. 2016;16(10):626-38.

https://doi.org/10.1038/nri.2016.90

18. Robinson DP, Huber SA, Moussawi M, Roberts B, Teuscher $C$, Watkins $\mathrm{R}$, et al. Sex chromosome complement contributes to sex differences in coxsackievirus B3 but not influenza A virus pathogenesis. Biol Sex Differ. 2011;2:8.

https://doi.org/10.1186/2042-6410-2-8

19. Jones BG, Sealy RE, Penkert RR, Surman SL, Birshtein BK, Xu $B$, et al. From influenza virus infections to lupus: Synchronous estrogen receptor $a$ and RNA polymerase II binding 
within the immunoglobulin heavy chain locus. Viral Immunol. 2020;33(4):307-15.

https://doi.org/10.1089/vim.2019.0144

20. Heath WR, Kato Y, Steiner TM, Caminschi I. Antigen presentation by dendritic cells for B cell activation. Curr Opin Immunol. 2019;58:44-52.

https://doi.org/10.1016/j.coi.2019.04.003

21. Laffont S, Seillet C, Guery JC. Estrogen receptor-dependent regulation of dendritic cell development and function. Front Immunol. 2017;8:108.

https://doi.org/10.3389/fimmu.2017.00108

22. Mai T, Zan H, Zhang J, Hawkins JS, Xu Z, Casali P. Estrogen receptors bind to and activate the HOXC4/HoxC4 promoter to potentiate HoxC4-mediated activation-induced cytosine deaminase induction, immunoglobulin class switch DNA recombination, and somatic hypermutation. J Biol Chem. 2010;285(48):37797-810. https://doi.org/10.1074/jbc.M110.169086

23. Pauklin S, Sernández IV, Bachmann G, Ramiro AR, Petersen-Mahrt SK. Estrogen directly activates AID transcription and function. J Exp Med. 2009;206(1):99-111.

https://doi.org/10.1084/jem.20080521

24. Jones BG, Penkert RR, Surman SL, Sealy RE, Pelletier S, Xu $B$, et al. Matters of life and death: How estrogen and estrogen receptor binding to the immunoglobulin heavy chain locus may influence outcomes of infection, allergy, and autoimmune disease. Cell Immunol. 2019;346:103996.

https://doi.org/10.1016/j.cellimm.2019.103996

25. Grimaldi CM, Jeganathan V, Diamond B. Hormonal regulation of $B$ cell development: $17 \mathrm{~b}$-estradiol impairs negative selection of high-affinity DNA-reactive B cells at more than one developmental checkpoint. J Immunol. 2006;176(5): 2703-10.

https://doi.org/10.4049/jimmunol.176.5.2703

26. Mo R, Chen J, Grolleau-Julius A, Murphy HS, Richardson BC, Yung RL. Estrogen regulates CCR gene expression and function in T lymphocytes. J Immunol. 2005;174(10):6023-9. https://doi.org/10.4049/jimmunol.174.10.6023

27. Channappanavar R, Fett C, Matthias Mack, Ten Eyck PP, Meyerholz DK, Perlman S. Sex-based differences in susceptibility to SARS-CoVinfection.JImmunol.2017;198(10):404653.

https://doi.org/10.4049/jimmunol.1601896

28. Wan Y, Shang J, Graham R, Baric RS, Li F. Receptor recognition by novel coronavirus from Wuhan: An analysis based on decade-long structural studies of SARS. J Virol. 2020; 94(7):e00127-20.

https://doi.org/10.1128/JVI.00127-20

29. Wrapp D, Wang N, Corbett KS, Goldsmith JA, Hsieh C, Abiona O, et al. Cryo-EM structure of the 2019-nCoV spike in the prefusion conformation. Science. 2020;367(6483):1260-3. https://doi.org/10.1126/science.abb2507
30. National Center for Biotechnology Information (NCBI). Bethesda, MD, USA: National Library of Medicine (US), National Center for Biotechnology Information; 1988. Available from: https://www.ncbi.nlm.nih.gov/protein.

31. Berman HM, Westbrook J, Feng Z, Gilliland G, Bhat TN, Weissig $\mathrm{H}$, et al. The Protein Data Bank. Nucleic Acids Res. 2000;28(1):235-42.

https://doi.org/10.1093/nar/28.1.235

32. Souza PCT, Textor LC, Melo DC, Nascimento AS, Skaf MS, Polikarpov I. An alternative conformation of ER $\beta$ bound to estradiol reveals $\mathrm{H} 12$ in a stable antagonist position. Sci Rep. 2017;7(1):3509.

https://doi.org/10.1038/s41598-017-03774-X

33. Pereira de Jésus-Tran K, Côté PL, Cantin L, Blanchet J, Labrie F, Breton R. Comparison of crystal structures of human androgen receptor ligand-binding domain complexed with various agonists reveals molecular determinants responsible for binding affinity. Protein Sci. 2006;15(5):987-99.

https://doi.org/10.1110/ps.051905906

34. BLAST [Internet]. Bethesda, MD, USA: National Library of Medicine (US), National Center for Biotechnology Information; 2004. [cited 15.05.2020.]. Available from: https://blast. ncbi.nlm.nih.gov/Blast.cgi.

35. Söding J, Biegert A, Lupas AN. The HHpred interactive server for protein homology detection and structure prediction. Nucleic Acids Res. 2005;33(Suppl. 2):W244-8.

https://doi.org/10.1093/nar/gki408

36. Altschul SF, Madden TL, Schäffer AA, Zhang J, Zhang Z, Miller W, Lipman DJ. Gapped BLAST and PSI-BLAST: A new generation of protein database search programs. Nucleic Acids Res. 1997;25(17):3389-402.

https://doi.org/10.1093/nar/25.17.3389

37. Altschul SF, Wootton JC, Gertz EM, Agarwala R, Morgulis A, Schäffer AA, Yu YK. Protein database searches using compositionally adjusted substitution matrices. FEBS J. 2005; 272(20):5101-9.

https://doi.org/10.1111/j.1742-4658.2005.04945.x

38. PyMOL ${ }^{\mathrm{TM}}$, v. 2.3.4, Schrödinger, LLC., New York, NY, USA; 2020. Available from: https://pymol.org/.

39. Li F. Structure, function, and evolution of coronavirus spike proteins. Annu Rev Virol. 2016;3:237-61.

https://doi.org/10.1146/annurev-virology-110615-042301

40. Xia S, Liu M, Wang C, Xu W, Lan Q, Feng S, et al. Inhibition of SARS-CoV-2 (previously 2019-nCoV) infection by a highly potent pan-coronavirus fusion inhibitor targeting its spike protein that harbors a high capacity to mediate membrane fusion. Cell Res. 2020;30(4):343-55.

https://doi.org/10.1038/s41422-020-0305-x

41. Weiss RA. Exchange of genetic sequences between viruses and hosts. In: Hunter E, Bister K, editors. Viruses, genes, and cancer. Current topics in microbiology and immunology, vol. 407. Cham, Switzerland: Springer; 2017. pp. 1-29.

https://doi.org/10.1007/82_2017_21 